\title{
Incidence of stroke in Oxfordshire: first year's experience of a community stroke register
}

\author{
OXFORDSHIRE COMMUNITY STROKE PROJECT
}

\begin{abstract}
The Oxfordshire Community Stroke Project is a prospective study of all new cases of stroke and transient ischaemic attack in a defined population of about 103000 patients registered with 49 general practitioners; every case is assessed by a neurologist and most patients undergo a CT scan or are examined post mortem, or both, to ensure accurate diagnosis.

Out of 404 cases registered in the first year, 168 patients had suffered a first stroke, 52 a recurrent stroke, and 41 a transient ischaemic attack; 143 were excluded. Of the 168 patients with their first stroke, $153(91 \%)$ were seen by a neurologist and $149(89 \%)$ had a CT scan or came to necropsy. The pathological diagnosis was cerebral infarction in 127 cases $(76 \%)$, intracranial haemorrhage in $22(13 \%)$, and unknown in $19(11 \%)$.

The estimated yearly incidence of first stroke was $1.95 / 1000$ population (age adjusted to 1981 population of England and Wales).
\end{abstract}

\section{Introduction}

Since 1955 there have been at least 13 major British studies of cerebrovascular disease in the community. ${ }^{1-13}$ Many, however, used methods that might have lead to selection bias, and little information has been provided on important topics such as the

The project is being coordinated by the departments of clinical neurology (Dr P A G Sandercock, Dr C P Warlow, Mrs S M Price), neuroradiology (Dr A Molyneux), neuropathology (Dr J T Hughes), and community medicine and general practice (Professor $M$ Vessey, Dr $\mathrm{K}$ McPherson, Dr G Fowler, Mrs L Jones), Radcliffe Infirmary, Oxford.

The following general practices have collaborated (names of liaison partners only): Dr A McPherson, Oxford; Dr A Markus, Thame; Dr D Leggatt, Oxford; Dr M Agass, Berinsfield; Dr D Otterburn, Abingdon; Dr S Street, Kidlington; Dr V M Drury, Wantage; Dr R Pinches, Abingdon; Dr N Crossley, Abingdon; Dr H O'Donnell, Deddington.

This paper was prepared by Dr P A G Sandercock, Dr C P Warlow, and Mrs S M Price, Radcliffe Infirmary, Oxford.

Correspondence and requests for reprints to: Dr P A G Sandercock, Acting Clinical Lecturer in Neurology, Radcliffe Infirmary, Oxford OX2 6HE. relative frequencies of cerebral haemorrhage and infarction and the role of computed tomography (CT) in the management of stroke. Stroke is the commonest cause of severe disability in the community, ${ }^{14}$ and these patients are estimated to consume about $5 \%$ of all health resources. ${ }^{15}$ Accurate information about incidence, management, and outcome should therefore be available to those responsible for planning in the health and social services and to clinicians concerned with the treatment and prevention of cerebrovascular disorders.

A community stroke register can provide such information, provided that the three main sources of inaccuracy are avoidedincomplete ascertainment, inaccuracy of clinical diagnosis, and inaccuracy of pathological diagnosis. Complete ascertainment of all new cases of stroke and transient ischaemic attack in a community depends primarily on close liaison with general practitioners, some $40 \%^{18}$ to $94 \% \%^{2}$ of all patients with these conditions being managed at home in Britain. Of the published British surveys, two did not achieve any contact and eight only infrequent contact with general practitioners. The diagnosis of stroke or transient ischaemic attack is largely based on clinical features, and the differential diagnosis, particularly for transient ischaemic attack, is often difficult. Wiebers and Whisnant ${ }^{17}$ suggested that surveys of cerebrovascular disease should rely on a neurological assessment as soon after the event as possible; only one British study ${ }^{2}$ has fulfilled this criterion. It is also essential to determine the type of lesion in every case, since clinical judgment does not reliably distinguish haemorrhagic from occlusive stroke $\mathrm{e}^{18}$ and intracranial space occupying lesions may occasionally mimic either stroke or transient ischaemic attack. Marquardsen noted ${ }^{19}$ that studies before the era of the CT scan were able to achieve an accurate pathological diagnosis in only about $30 \%$ of cases of stroke and that there was therefore a need for community based studies of stroke which used CT.

Oxfordshire was judged to be an ideal setting for an accurate community stroke register, since several general practices wanted to collaborate and we had the Oxfordshire Record Linkage System ${ }^{20}$ a neurological department with an established interest in cerebrovascular disease, and adequate radiological facilities. We therefore had the potential to identify a population in which ascertainment of both hospital and home cases was as complete as possible and clinical and pathological diagnosis was accurate. Such a study was begun on 1 November 1981, and this paper reports the results at one year. 


\section{Methods}

\section{STUDY POPULATION}

The study population comprises all patients fully registered with the 49 general practitioners (from 10 group practices) collaborating in the study. The practices are distributed between urban and rural Oxfordshire, and the patients.come from all social classes and occupations. Patients who suffer a stroke or transient ischaemic attack while outside the study area but who nevertheless are registered with one of the practices are included. The size of population was measured by a census of the age and sex registers in each practice in November and December 1981 and will be measured again at regular intervals. Since such registers are known to be inaccurate, ${ }^{21}$ the numbers in the age groups $0-64,65-74$, and 75 and over were checked against those held by the Oxfordshire Family Practitioner Committee.

\section{NEUROLOGICAL DEFINITIONS}

Transient ischaemic attack is defined as acute loss of focal cerebral or ocular function with symptoms lasting less than 24 hours and which after adequate investigation is presumed to be due to embolic or thrombotic vascular disease. ${ }^{22}$

Stroke is defined as rapidly developing clinical signs of focal and at times global (applied to patients in deep coma and to those with subarachnoid haemorrhage) loss of cerebral function, with symptoms lasting more than 24 hours or leading to death, with no apparent cause other than that of vascular origin (WHO definition). ${ }^{23}$ The appendix defines the different pathological types of stroke.

\section{COLLABORATION WITH GENERAL PRACTITIONERS}

Each of the practices has designated a "liaison partner," who checks regularly with all other partners to ensure that all new cases in the practice are referred to the study. The research team (PAGS, CPW, SMP) meets all the liaison partners about every three months to discuss the progress and results of the study, resolve any organisational difficulties, and plan future objectives. The team also visited each of the practices for informal discussions both at the start of the study and at the end of the first year.

The research nurse visits each liaison partner at least weekly, and the study neurologist visits each practice about every eight weeks.

A monthly newsletter is sent to every participant in the study, along with an up to date diagnostic list of all patients referred by the practice.

\section{METHOD OF REFERRAL}

To facilitate easy referral we ask only the patient's name and address; as most referrals are by telephone, the study office has its own line and an answerphone for out of hours calls. We also provide simple forms with prepaid envelopes for written notifications.

\section{CHECKS ON COMPLETENESS OF ASCERTAINMENT}

Hospital admission registers-Checks are made at least twice weekly in all the hospitals in the Oxford area for patients admitted with stroke, transient ischaemic attack, subarachnoid haemorrhage, or suspected stroke. Patients admitted with diagnoses such as "collapse," "coma," "dizziness," and "confusion" are also assessed.

The Oxford Record Linkage Study has been described elsewhere." It enables all patients who die in or are discharged from a hospital in the Oxford region with a given diagnosis to be identified. The study regularly provides us with lists of patients with diagnoses coded to the International Classification of Diseases (ninth revision) rubrics 430-438 and 342 (hemiplegia NOS).

Death certificates-Community physicians provide copies of the death certificates of all patients dying in Oxfordshire, and the records of any certified as dying from cerebrovascular disease who are registered with one of the study practices are then obtained. All cases referred to the coroner are also included.

Diagnostic indexes-Two of the practices have computerised diagnostic indexes, and the departments of neurology and neurosurgery also have indexes, which are used as additional sources of information.

\section{PATIENT ASSESSMENT}

The study neurologists aim to see the patients as soon after the event as possible. Assessment consists of a clinical history and examination (details of the methods and questionnaire provided on request), supplemented by an interview with a witness if possible. Data on all past illnesses are then extracted from every available medical record, including that of the general practitioner. A written report of the assessment and results of investigations is sent to the patient's general practitioner, but no advice on management is given unless requested.

To ensure that diagnostic standards remain uniform, the study team meets weekly to discuss each new case and revise the diagnoses in any old cases if new information-for example, from necropsy or further clinical investigation-has come to light.

\section{PATHOLOGICAL DIAGNOSIS}

A CT scan without intravenous contrast enhancement is performed on each patient as soon as possible after the event using an EMI 1007 $160+160$ matrix scanner; intravenous contrast is given only if clinically indicated. The CT scan is reported "blind" by the study radiologist, and if there is doubt about the presence or absence of a lesion the scan is again reviewed blind at a later date. If it is not possible to perform a CT scan then every effort is made to ensure that necropsy is performed in the event of death.

\section{DATA COLLECTION AND ANALYSIS}

All data are collected on precoded forms and transferred to punched cards for entry to the computer (ICL 2988), where they are analysed using the statistical package for social sciences. ${ }^{24}$ Confidence intervals for age specific rates were calculated using the standard method for confidence interval of a proportion. ${ }^{25}$

\section{Results}

Population census-The first census of the practices' age and sex registers was taken in November and December 1981. The study population numbered 102613 . The figure compares the age structure of the study population with the 1981 Census data for Oxfordshire. The age structures were very similar, especially for those over 65 , among whom stroke is commonest. To check the accuracy of the census, results from the age and sex registers (ASR) were compared with data from the family practitioner committee (FPC) records. The discrepancies ([FPC-ASR/ASR] $\times 100)$ between the two totals were: age $0-64,+1.92^{\prime \prime}$; age $65-74,-1.72^{\prime \prime}$; age $75,-8.27^{\circ}$; all ages, $-1 \cdot 2{ }^{\prime \prime}{ }_{1}$. These were not as wide as reported elsewhere. ${ }^{21}$

Notifications-During the first year of the study 404 patients were registered, of whom 168 had suffered a first stroke (including nine cases of spontaneous subarachnoid haemorrhage), 52 a recurrent stroke, and 41 a transient ischaemic attack; 143 were excluded. At least 11 of the patients referred as ?transient ischaemic attack were reclassified as "completed stroke" after neurological assessment. The division between those referred as ?transient ischaemic attack

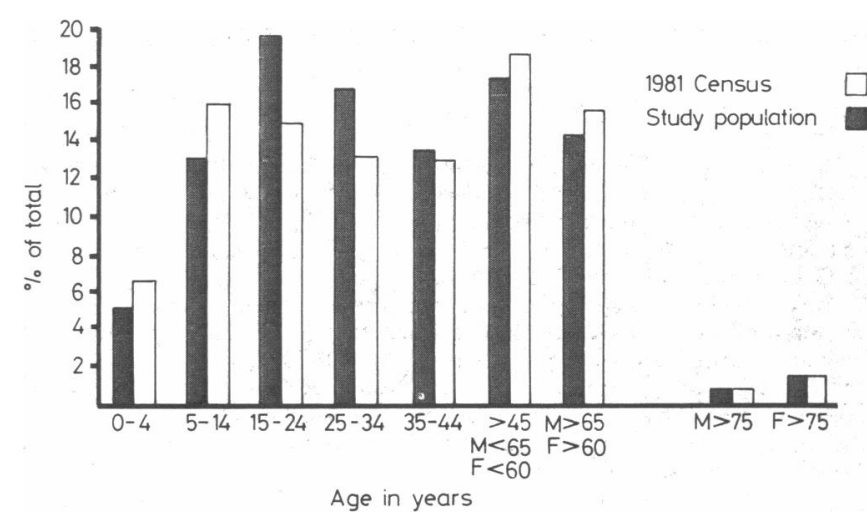

Age structure of study population compared with Oxfordshire (1981 Census) Age bands are unusual because of way provisional census data are given 
and ?stroke is not particularly accurate, since the referring doctor is not required to give a definite diagnosis at the time of referral. The sources of notification for the 168 patients with first strokes were: general practitioner $145\left(86.3^{\prime \prime}{ }_{10}\right)$, admission register $18\left(10 \cdot 7^{\prime \prime}{ }_{10}\right)$, Oxford Record Linkage Study $1\left(0 \cdot 6^{\prime \prime}{ }_{0}\right)$, and death certificate $4\left(2 \cdot 4^{\circ}{ }^{\circ}\right)$. Of the 23 patients not referred by a general practitioner, eight were admitted after emergency ambulance calls without the general practitioner's knowledge and four were admitted by other doctors without the general practitioner being informed, one refused contact with the study. Thus there were only 10 out of 168 cases $\left(6^{\circ}{ }_{11}\right)$ where the general practitioner forgot to inform the study.

Speed of notification and assessment-Of the 168 patients with first strokes, $142\left(85^{\circ}{ }_{11}\right)$ were referred within seven days of onset. Of the 153 who were alive at the time of notification, $121\left(79^{\prime \prime \prime}{ }_{1}^{\prime}\right)$ were seen by the study neurologist within seven days of onset and $138\left(90^{\prime \prime}{ }_{11}\right)$ within 14 days.

Admission to hospital-Sixty nine of the 168 patients with first strokes $\left(41^{\prime \prime}\right.$ ) $)$ were admitted to hospital immediately after the event. Five patients who had strokes while on holiday were managed in hospitals outside the Oxford area.

Pathological diagnosis-Table I gives the results of the CT scan and necropsy in the 168 cases of first stroke. Table II shows the intervals between onset of the stroke and the time of the CT scan. Of the 19 patients whose type of stroke was not known, six were still alive (and may yet come to necropsy) and 13 had died without scan or necropsy. Of these 13, six died less than 24 hours after the onset of the stroke and therefore probably had cerebral haemorrhages, ${ }^{25}$ a disproportionate number in comparison with the whole group. Nevertheless, even if all the cases of "stroke type not known" are added to the haemorrhage group haemorrhages would still account for only $41\left(24^{\prime \prime}{ }_{11}\right)$ of the 168 strokes.

Incidence of first stroke-Table III gives the age specific rates for

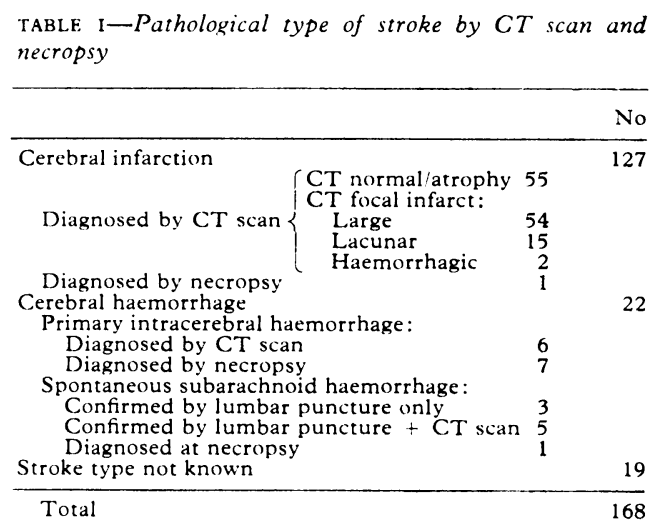

TABLE II-Interval (days) between onset of stroke and CT scan (137 cases)

\begin{tabular}{lrrrrrrrrrr}
\hline $\begin{array}{l}\text { Days after onset } \\
\text { No of cases }\end{array}$ & $\leqslant 3$ & -7 & -11 & -15 & -19 & -23 & -27 & -31 & -35 & $\geqslant 36$ \\
& 24 & 34 & 20 & 14 & 11 & 7 & 5 & 3 & 0 & 19
\end{tabular}

TABLE III-Yearly age and sex specific incidence rates/1000 for first stroke

\begin{tabular}{|c|c|c|c|}
\hline $\begin{array}{c}\text { Age } \\
\text { (years) }\end{array}$ & $\begin{array}{l}\text { No of cases/ } \\
\text { No at risk }\end{array}$ & Rate & $\begin{array}{c}95 . \text { confidence } \\
\text { interval }\end{array}$ \\
\hline \multicolumn{4}{|c|}{ Men } \\
\hline $\begin{array}{r}0-54 \\
55-64 \\
65-74 \\
\geqslant 75\end{array}$ & 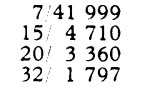 & $\begin{array}{r}0.17 \\
3.18 \\
5.95 \\
17 \cdot 82\end{array}$ & $\begin{array}{r}0.04-0.29 \\
1.58-4.79 \\
3.35-8.55 \\
11.69-23.9\end{array}$ \\
\hline \multicolumn{4}{|c|}{ W'omen } \\
\hline $\begin{array}{r}0-54 \\
55-64 \\
65-74 \\
\geqslant 75\end{array}$ & $\begin{array}{r:rr}6 & 38 & 797 \\
14 & 4 & 796 \\
26 & 3 & 776 \\
48 & 3 & 379\end{array}$ & $\begin{array}{r}0 \cdot 16 \\
2 \cdot 92 \\
6 \cdot 89 \\
14 \cdot 21\end{array}$ & $\begin{array}{r}0.03-0.28 \\
1.39-4.45 \\
4.25-9.52 \\
10.22-18.20\end{array}$ \\
\hline \multicolumn{4}{|c|}{ Men + Women } \\
\hline $\begin{array}{r}0-54 \\
55-64 \\
65-74 \\
\geqslant 75 \\
\end{array}$ & $\begin{array}{l:ll}13 & 80 & 796 \\
29 & 9 & 506 \\
46 & 736 \\
80 & 5 & 175 \\
\end{array}$ & $\begin{array}{r}0.16 \\
3.05 \\
6.45 \\
15.46 \\
\end{array}$ & $\begin{array}{r}0 \cdot 07-0 \cdot 25 \\
1.94-4 \cdot 16 \\
4 \cdot 59-8 \cdot 30 \\
12 \cdot 10-18 \cdot 82\end{array}$ \\
\hline Total & $168 / 102613$ & $1 \cdot 64$ & $1 \cdot 39-1 \cdot 88$ \\
\hline
\end{tabular}

first stroke and the $95 \%$ confidence intervals. If the denominator used in the calculation of the rates is adjusted to allow for the estimated error in the age and sex register census, the age specific rates for the age groups $65-74$ and $\Rightarrow 75$ and the crude rate for the whole study population change by $+1.71 \%$, $+9 \%$, and $-1.31 \%$ respectively. The yearly incidence rate for first stroke (age adjusted to the 1981 population of England and Wales by the direct method) is $1.95 / 1000$. It is not possible to estimate any error in the age adjusted rate for England and Wales, since the family practitioner committee does not provide data on the size of age groups for those under 65 . The rates at all ages for first stroke are, however, very similar to estimates from other centres in Britain and Europe.' 13102629

\section{Discussion}

A properly organised register of cases of stroke and transient ischaemic attack provides data on an unselected and therefore representative sample of the community. Since the data from stroke registers are so widely applicable, it is important that they should be as accurate as possible-which means that ascertainment should be complete, clinical diagnosis should be accurate, and the pathological diagnosis should be established in every case.

Completeness of ascertainment is easy to check if most patients with stroke are admitted to hospital, as in Frederiksburg, Denmark. ${ }^{26}$ But when many cases of stroke and almost all of transient ischaemic attack are managed at home, ${ }^{8}$ the emphasis must be on collaborating with general practitioners. Experience from other large community studies shows that contact with general practitioners needs to be regular, frequent, and to take several different forms. Methods such as visits by a research nurse, newsletters, and "feedback" on individual patients, informal contacts between all the participants, and regular meetings must be used if momentum and enthusiasm for the study are to be maintained. We appear to have been successful in this respect, judging from the preliminary results. Firstly, although checks of all other available sources of information such as admission registers of local hospitals and death certificates produced 23 new cases $(13.7 \%$ of all first strokes), most of the instances where a general practitioner apparently failed to notify a case resulted from the patient being admitted to hospital without his knowledge. Secondly, general practitioners have referred cases rapidly $(85 \%$ within seven days of onset) and have also notified five cases of stroke occurring while the patients were out of the area. Thirdly, we believe that the general practitioners have referred more minor strokes in this study than previous ones, as a direct result of the very close liaison. Completeness of ascertainment has been further enhanced by running a transient ischaemic attack register concurrently; at least 11 of the cases referred as ?transient ischaemic attack fulfilled the criteria for completed stroke. Finally, only $41 \%$ of the patients were admitted to hospital, which is lower than in some other studies ${ }^{4}{ }^{8}$; though there may be several reasons for this, a likely explanation is that studies with an apparently high admission rate to hospital are simply failing to detect the milder cases managed at home.

Clinical differentiation of "stroke" from "non-stroke" is reasonably reliable, ${ }^{18}$ though the clinical diagnosis of transient ischaemic attack is more difficult; ideally the diagnosis should be made by a neurologist soon after the event if the assessment is to be accurate. ${ }^{17}$ In this study $91{ }^{\circ}$ of patients were seen by a neurologist; and of those alive at the time of notification, $79 \%$ were seen within seven days of the onset. Clearly this is more satisfactory than diagnoses based purely on case note review, as in the studies of Brewis et $a l^{1}$ and Acheson and Fairbairn, ${ }^{3}$ though it is not as impressive as the mean interval of 40 minutes between onset and assessment achieved by Garraway et al ${ }^{28}$ (their study, however, used a much larger team, and did not aim at completeness of ascertainment).

Establishing the pathological type of stroke in a community or even hospital sample of patients was not feasible until the CT scan was introduced, and although studies have been 
published of stroke registers employing CT on most patients admitted to hospital, ${ }^{29}{ }^{30}$ none have yet used CT on the majority of patients from both home and hospital. There are inevitably a few patients in whom it is not possible to obtain a CT scan, usually because they die within hours of onset, and it is vital to ensure that a necropsy is performed on these patients, as they are much more likely to have had a cerebral haemorrhage ${ }^{26}$; only one community based study ${ }^{31}$ has achieved a high necropsy rate in such cases. We reached a pathological diagnosis by CT scan in 137 out of 168 cases of first stroke $\left(81^{\circ} \%\right)$, by necropsy in a further nine cases, and by lumbar puncture in a further three; in only 19 cases $(11 \%)$ could the type of stroke not be determined. Cerebral infarction occurred in $76^{\circ} \%$ and intracranial haemorrhage (including subarachnoid haemorrhage) in $13^{\circ} \%$ This is surprisingly similar to findings of studies performed before the advent of CT, since we might have expected the CT scan to detect the small non-fatal intracerebral haemorrhages that mimic the clinical picture of cerebral infarction. ${ }^{3.2}$ One speculative reason for the similarity between our results and others is that by including more of the milder cases with cerebral infarction than earlier studies our survey has diluted the effect of increased detection of small cerebral haemorrhages. A difficulty with our study has been to ensure that the CT scan is done before the onset of the "fogging" effect. ${ }^{33}$ Our inability to do so may explain why $40 \%$ of patients had a normal scan. Administering intravenous contrast might have increased the detection rate, but it was not done routinely for various reasons, not least being the suggestion that intravenous contrast may worsen the outcome. ${ }^{34}$ We intend to repeat the scans in survivors at six months, when detection of cerebral infarcts improves again. ${ }^{34}$ None the less, $78 \%$ of the scans were performed within 21 days of onset, which should ensure that most cerebral haemorrhages were detected. ${ }^{35}$

The next consideration must be the accuracy of the denominator used to calculate the incidence rates. Most published studies referred to were based on geographical areas, which allowed the use of national census data to estimate the population at risk; this study has defined its population differently and therefore has to rely to a large extent on the age and sex registers of the participating practices. The discrepancy between the age and sex registers and the family practitioner committee data are not great, and certainly not as great as reported elsewhere. ${ }^{20}$ Furthermore, even if an allowance is made for the discrepancy between the two sets of figures in calculating the crude incidence rates and age specific incidence rates for the 65-74 and over 75 age groups, the rates do not change a great deal. A further criticism of our study is that the sample is not random. We do know, however, that the age and sex structure of the sample matches that of Oxfordshire very closely (see figure), particularly in those aged over 65 . Since the practices included in the study also cover all social classes and encompass the whole of a moderate sized town (Abingdon) with a population of some 33000 , it is unlikely that the social class distribution of the sample is atypical.

Finally, we hope that we have overcome one criticism of other stroke registers in Britain-that the information is put to limited use, thus wasting the considerable effort entailed. In this study the patients aged under 76 are the index cases in a case-control study of the importance of cardiac disease in stroke, all suitable cases of transient ischaemic attack (TIA) are entered into the UK-TIA aspirin trial, the CT scan results are used to validate a clinical scoring system for the differentiation of haemorrhage from infarction, and the community physicians are already beginning to use the data for health care planning.

This work is being supported by a grant from the Medical Research Council. We thank the participating general practitioners and the consultant physicians and surgeons who have allowed us to study their patients. We also thank all the practice receptionists and nursing staff, who have helped in many ways, and the voluntary car drivers of Oxfordshire, who have provided invaluable help in transporting patients.

\section{Appendix}

DEFINITIONS OF DIFFERENT PATHOLOGICAL TYPES OF STROKE

Spontaneous subarachnoid haemorrhage-This definition was adapted from that used by the ARCOS study. ${ }^{36}$ It comprises a clinical picture of abrupt onset of severe headache or loss of consciousness or both with or without focal neurological features and with at least one of the following clinical signs: (1) lumbar puncture findings of uniform blood staining (red blood cells $2 \times 10^{9} / 1$ ) or xanthochromia or both; (2) cerebral angiographic identification of a saccular aneurysm or arteriovenous malformation as the source of bleeding; (3) CT scan evidence of blood in the fissure of Sylvius, between the frontal lobes, in basal cisterns, or within a ventricle; (4) bleeding saccular aneurysm or arteriovenous malformation found at operation; (5) necropsy evidence of recent bleeding of saccular aneurysm or arteriovenous malformation. The definition excludes patients with primary intracerebral haemorrhage with rupture into the subarachnoid spaces or rupture due to trauma, neoplasms, or infections.

Primary intracerebral haemorrhage was defined as a stroke caused by non-traumatic bleeding, primarily into brain substance, with or without the presence of blood in the subarachnoid space. Intracerebral haematoma must be confirmed by CT or necropsy.

Cerebral infarction was defined as a stroke caused by infarction of cerebral tissue, confirmed by CT scan or at necropsy. Patients with clinically definite strokes in whom the CT scan is normal are also classified as having suffered a cerebral infarct; the diagnosis is therefore one of exclusion and relies on two factors-accurate clinical diagnosis of completed stroke, and exclusion of cerebral haemorrhage.

Stroke of uncertain type is recorded when a patient has suffered a clinically definite completed stroke but has not had a CT scan or come to necropsy.

\section{References}

' Brewis M, Poskanzer DC, Rolland C, Miller H. Neurological disease in an English city. Acta Neurol Scand 1966;suppl 24:42.

- Acheson J, Acheson HWK, Tellwright JM. The incidence and pattern of cerebrovascular disease in general practice. $\mathcal{F} R$ Coll Gen Pract 1968; $16: 428-36$.

${ }^{3}$ Acheson RM, Fairbairn RS. Burden of cerebrovascular disease in the Oxford area in 1963 and 1964. Br Med 71970 ;ii:621-6.

1 Royal College of Physicians. Report of the Geriatrics Committee. London: Royal College of Physicians, 1974.

'Logan WPD, Cushion AA. Morbidity statistics from general practice. Vol 1 (general). Studies on medical and population subjects. No 14 . London: HMSO, 1958.

${ }^{6}$ Royal College of General Practitioners. Morbidity statistics 1971-2, second national study. Studies on medical and population subjects. No 36. London: HMSO, 1979.

Weddell JM, Beresford SAA. Planning for stroke patients. London: HMSO, 1979.

"Chin PL, Angunawela R, Mitchell D, et al. Stroke register in Carlisle: a preliminary report. In: Rose FC, ed. Clinical neuroepidemiology. Tunbridge Wells: Pitman Medical, 1980.

${ }^{y}$ Brocklehurst JC, Andrews K, Morris PE. Medical social and psychological aspects of stroke in elderly patients. Final report. Manchester: University of Manchester Department of Geriatric Medicine, 1978

${ }^{10}$ Rankin J. Cerebrovascular accidents in patients over the age of 60 . II. Prognosis. Scott Med f 1957;2:200-15.

$"$ Grimley Evans J, Prudham D, Wandless I. Risk factors for stroke in the elderly. In: Barbagallo G, ed. The Ageing brain. New York: Plenum, 1980.

1:2 Stevens RS, Ambler NR. The incidence and survival of stroke patients in a defined community. Age Ageing 1982;11:266-74.

1:3 Waters HJ, Perrin JM. Study of stroke patients in a single general practice. Br Medf $1982 ; 284: 791-3$.

14 Harris AI. Handicapped and impaired in Great Britain. London: HMSO, 1971

15. Carstairs V. Stroke: resource consumption and the cost to the community. In: Gillingham FJ, Mawdsley C, Williams AE, eds. Stroke. Proceedings of the ninth Pfizer international symposium. London: Churchill Livingstone, 1976.

16. Cochrane AL. Burden of cerebrovascular disease. Br Med f 1970;iii : 165.

17 Wiebers DO, Whisnant JP. Epidemiology. In: Warlow CP, Morris PJ, eds. Transient ischemic attacks. New York: Marcel Dekker Inc, 1982:4.

is Von Arbin M, Britton M, de Faire $M$, et al. Accuracy of bedside diagnosis of stroke. Stroke $1981 ; \mathbf{1 2}: 288-93$.

${ }^{19}$ Marquardsen J. An epidemiologic study of stroke in a Danish urban community. In: Gillingham FJ, Mawdsley C, Williams AE, eds. Stroke. Proceedings of the ninth Pfizer international symposium. London: Churchill Livingstone, 1976.

"Acheson ED. Medical record linkage. London: Oxford University Press, 1967. 
${ }^{21}$ Fraser RC, Clayton DG. The accuracy of age-sex registers, practice medical records and family practitioner committee registers. $\mathcal{f} R$ Coll Gen Pract $1981 ; 31: 410-9$.

22 Warlow CP, Morris PJ. Transient ischemic attacks. New York: Marcel Dekker Inc, 1982 :ix.

${ }^{23}$ Hatano S. Experience from a multicentre stroke register, a preliminary report. Bull WHO 1976;54:541-53.

${ }^{24} \mathrm{Nie} \mathrm{NH}$, Hull $\mathrm{CH}$, Jenkins JG, et al. Statistical package for the social sciences. New York: McGraw Hill, 1975.

${ }^{25}$ Armitage P. Statistical methods in medical research. Oxford: Blackwell Scientific, 1971:114.

${ }^{26}$ Phillips LH, Whisnant JP, Reagan TJ. Sudden death from stroke. Stroke 1977;8:392-5.

${ }^{27}$ Hansen BS, Marquardsen J. Incidence of stroke in Frederiksberg, Denmark. Stroke 1977;8:633-5.

${ }^{28}$ Garraway WM, Akhtar AJ, Smith DL, et al. The triage of stroke rehabilitation. I Epidemiol Community Health 1981 ;35:39-44.

${ }^{29}$ Herman B, Leyten ACM, Luijk JH, et al. Epidemiology of stroke in Tilburg, the Netherlands: the population based stroke incidence register 2 . Incidence, initial clinical picture and three week case fatality. Stroke 1982;13:629-34.

${ }^{30}$ Mohr JP, Caplan LR, Melski JW, et al. The Harvard Cooperative Stroke Registry: a prospective registry. Neurology 1978;28:754-62.

31 Uedo K, Omae T, Hirota Y, et al. Decreasing trend in incidence and mortality from Hisayama residents, Japan. Stroke 1981;12:154-60.

32 Allen CMC. Clinical diagnosis of the acute stroke syndrome. $Q \mathcal{F} \mathrm{Med}$ (in press).

${ }^{33}$ Skriver EB, Olsen TS. Contrast enhancement of cerebral infarcts, incidence and clinical value in different states of cerebral infarction. Neuroradiology $1982 ; 23: 259-65$.

${ }^{34}$ Pullicino C, Kendall BE. Contrast enhancement in ischaemic lesions. Neuroradiology 1980;19:235-9.

${ }^{35}$ Kinkel WR, Jacobs L. Computerized axial transverse tomography in cerebrovascular disease. Neurology 1976;26:924-30.

${ }^{36}$ Bonita R. Suggested criteria for primary subarachnoid haemorrhage. Monica News (WHO Geneva) 1982;1:10.

\title{
Effect on intra-arterial blood pressure of slow release metoprolol combined with placebo or chlorthalidone
}

\author{
H A KIESO, B A GOULD, S MANN, R S HORNUNG, D G ALTMAN, E B RAFTERY
}

\begin{abstract}
Thirty patients with essential hypertension participated in a double blind crossover trial in which they were randomly allocated to treatment with either once daily slow release metoprolol $(200 \mathrm{mg})$ with placebo or once daily slow release metoprolol $(200 \mathrm{mg}$ ) with chlorthalidone (25 $\mathrm{mg}$ ). Ambulatory intra-arterial blood pressure was recorded continuously for 24-48 hours before treatment and two months after each change in regimen. The response of blood pressure and pulse rate to a standard exercise protocol that included supine rest and tilt, isometric, and dynamic bicycle exercise was measured during the same recording periods. Both treatments appreciably reduced blood pressure and pulse rate; mean daytime intra-arterial blood pressure was reduced from $174 / 95 \mathrm{~mm} \mathrm{Hg}$ to $158 / 85 \mathrm{~mm} \mathrm{Hg}$ by metoprolol plus placebo and to $143 / 78 \mathrm{~mm} \mathrm{Hg}$ by metoprolol plus chlorthalidone. This reduction with the combined treatment was significantly greater than with metoprolol and placebo (p systolic $=0.001, p$ diastolic $=0.004$ ). Mean night time pressures were reduced from $148 / 78 \mathrm{~mm} \mathrm{Hg}$ to $139 / 75 \mathrm{~mm} \mathrm{Hg}$ by metoprolol plus placebo and to 116 / $61 \mathrm{~mm} \mathrm{Hg}$ by metoprolol plus chlorthalidone. Again the reduction in blood pressure was significantly greater with combined treatment $(p<0.001)$ than with metoprolol plus placebo.
\end{abstract}

Once daily slow release metoprolol is effective in controlling blood pressure, but this effect is greatly enhanced by the addition of a diuretic.

\footnotetext{
Department of Cardiology and Divisions of Clinical Sciences and Computing and Statistics, Northwick Park Hospital and Clinical Research Centre, Harrow, Middlesex

H A KIESO, MB, MRCP, research registrar

B A GOULD, MB, MRCP, registrar

$S$ MANN, MA, MRCP, research registrar

R S HORNUNG, $M B$, MRCP, research registrar

D G ALTMAN, BSC, medical statistician

E B RAFTERY, MD, FRCP, consultant cardiologist

Correspondence to: Dr E B Raftery, Northwick Park Hospital, Watford Road, Harrow, Middlesex HA1 3UJ.
}

\section{Introduction}

Metoprolol is a selective beta adrenoreceptor blocking agent ${ }^{1}$ that has been shown to lower the blood pressure during the day and at night and during dynamic exercise but not isometric exercise. ${ }^{2}$ Chlorthalidone is a long acting diuretic closely allied to the thiazides and the results of studies have shown that a combination of metoprolol and chlorthalidone is effective and well tolerated in mild to moderate hypertension. ${ }^{3}$ Once daily dosage with antihypertensive agents is desirable since it improves compliance, ${ }^{4}$ and metoprolol may maintain its hypotensive effect up to 26 hours after the last dose. ${ }^{5}$

We measured the effects of a single daily dose of a slow release formulation of metoprolol combined with either placebo or chlorthalidone to assess the effectiveness of the combination in terms of both absolute reduction of blood pressure and duration of effect. We also measured the effect of both combinations on blood pressure during a standardised exercise protocol.

\section{Patients and methods}

Thirty patients with uncomplicated essential hypertension (seven women, $23 \mathrm{men}$ ), aged from 36 to 65 years (mean 52 years) were recruited from the hypertension clinic. Patients were included if the mean of three blood pressures taken in the outpatient clinic measured by standard indirect techniques (diastolic=Korotkoff phase V) exceeded $160 \mathrm{~mm} \mathrm{Hg}$ systolic or $95 \mathrm{~mm} \mathrm{Hg}$ diastolic or both. The usual contraindications to beta adrenoreceptor blocking drugs and thiazides were observed. We have row undertaken several studies over three periods of intra-arterial monitoring without complications, and an internal audit of our first 1000 cannulations has shown only a few minor complications (unpublished data). We thus feel confident that there is no contraindication to three periods of intra-arterial blood pressure monitoring in a single patient. Informed consent was obtained, and the trial was approved by the hospital ethical committee.

The patients received no antihypertensive treatment for four weeks before the first study and were then randomly allocated to receive slow release metoprolol $200 \mathrm{mg}$ once daily with placebo or slow release metoprolol $200 \mathrm{mg}$ with $25 \mathrm{mg}$ chlorthalidone once daily, the allocation being double blind. Each patient was requested to take the tablets at 0800 and all were followed up in the hypertension clinic. After about eight weeks (range 7-9) the patients were studied a second time. Each was then switched to the alternative regimen for a further eight weeks, when a third study was performed. Each patient was seen at two 